\title{
Physicochemical Characteristics of Bone Substitutes Used in Oral Surgery in Comparison to Autogenous Bone
}

\author{
Antoine Berberi, ${ }^{1}$ Antoine Samarani, ${ }^{2}$ Nabih Nader, ${ }^{1}$ Ziad Noujeim, \\ Maroun Dagher, ${ }^{3}$ Wasfi Kanj, ${ }^{1}$ Rita Mearawi, ${ }^{1}$ Ziad Salemeh, ${ }^{1}$ and Bassam Badran ${ }^{2}$ \\ ${ }^{1}$ School of Dentistry, Lebanese University, P.O. Box 4, Hadath, Lebanon \\ ${ }^{2}$ Ecole Doctorale, PRASE, Lebanese University, P.O. Box 4, Hadath, Lebanon \\ ${ }^{3}$ Faculty of Dental Medicine, Saint Joseph University, P.O. Box 17-5208, Beirut, Lebanon \\ Correspondence should be addressed to Antoine Berberi; anberberi@gmail.com
}

Received 11 May 2014; Accepted 8 June 2014; Published 8 July 2014

Academic Editor: David M. Dohan Ehrenfest

Copyright (C) 2014 Antoine Berberi et al. This is an open access article distributed under the Creative Commons Attribution License, which permits unrestricted use, distribution, and reproduction in any medium, provided the original work is properly cited.

\begin{abstract}
Bone substitutes used in oral surgery include allografts, xenografts, and synthetic materials that are frequently used to compensate bone loss or to reinforce repaired bone, but little is currently known about their physicochemical characteristics. The aim of this study was to evaluate a number of physical and chemical properties in a variety of granulated mineral-based biomaterials used in dentistry and to compare them with those of autogenous bone. Autogenous bone and eight commercial biomaterials of human, bovine, and synthetic origins were studied by high-resolution X-ray diffraction, atomic absorption spectrometry, and laser diffraction to determine their chemical composition, calcium release concentration, crystallinity, and granulation size. The highest calcium release concentration was $24.94 \mathrm{mg} / \mathrm{g}$ for Puros and the lowest one was $2.83 \mathrm{mg} / \mathrm{g}$ for Ingenios $\beta$-TCP compared to $20.15 \mathrm{mg} / \mathrm{g}$ for natural bone. The range of particles sizes, in terms of median size D50, varied between $1.32 \mu \mathrm{m}$ for BioOss and $902.41 \mu \mathrm{m}$ for OsteoSponge, compared to $282.1 \mu \mathrm{m}$ for natural bone. All samples displayed a similar hexagonal shape as bone, except Ingenios $\beta$-TCP, Macrobone, and OsteoSponge, which showed rhomboid and triclinic shapes, respectively. Commercial bone substitutes significantly differ in terms of calcium concentration, particle size, and crystallinity, which may affect their in vivo performance.
\end{abstract}

\section{Introduction}

Bone is a living tissue that serves for structural support and calcium metabolism. Bone matrix is organic and consists of a network of collagen protein fibers impregnated with mineral salts $(85 \%$ of calcium phosphate, $10 \%$ of calcium carbonate, and $5 \%$ of calcium fluoride and magnesium fluoride). The mineral compartment of bone is predominantly present in the form of calcium hydroxyapatites $\left(\mathrm{Ca}_{10}\left[\mathrm{PO}_{4}\right]_{6}[\mathrm{OH}]_{2}\right)$. Bone tissue also contains negligible quantities of noncollagen proteins, including the family of bone morphogenetic proteins (BMPs) [1].

Calcium (Ca) plays an important role in osteoconductivity and may enhance bone tissue integration by entrapping and concentrating circulating bone growth factors (BMPs) and osteoprogenitor cells, thus imparting osteoinductive properties to calcium-based bone graft materials $[2,3]$.
Autogenous bone is osteogenic (cells within a donor graft synthesize new bone at implantation sites), osteoinductive (new bone is formed by active recruitment of host mesenchymal stem cells from surrounding tissue, which differentiate into bone-forming osteoblasts), osteoconductive (vascularization and new bone formation into the transplant), and highly biocompatible $[3,4]$. These characteristics should be present in an ideal substitute and all bone grafting materials can be classified according to these characteristics [5].

Bone substitutes (BS) are frequently used in oral and maxillofacial surgery, periodontics, and orthopedics. They include inorganic or organic, natural or synthetic materials to compensate for bone loss or to reinforce new bone ingrowth into defect sites [6-17]. This second option is, in fact, the role played by calcium phosphate and constitutes materials that show the closet similarity to the mineral component of bone 
[14]. The greatest success in bone grafting has been achieved with autogenous bone (gold standard), which fulfills all essential physicochemical and biological properties needed in a bone graft material, despite its inherent limitations in availability and postoperative pain at donor sites $[6,8,10,11$, 13, 18-20].

Numerous BS biomaterials have been successfully used, such as allografts (human), xenografts (porcine, equine, or bovine, and synthetic calcium-based materials (calcium phosphates $[\beta$-tricalcium phosphate/ $\beta$-TCP, hydroxyapatite/HA], bioactive glasses), calcium sulfate, calcium hydroxide), and a combination of these with or without the use of membrane and screws [6-23].

Allografts do not have the drawbacks of autografts but are less successful in clinical practice. They also display several other disadvantages: risk of disease transmission or infection, difficulties in obtaining and processing, possible rapid resorption, [8-10, 24], and partial loss of mechanical strength after sterilization $[25,26]$. Xenogenic bone substitutes of porcine, bovine, or, more recently, equine origin are used because of their chemical and structural composition similarity when compared to human bone [27]. They represent an unlimited supply of available material and may reduce morbidity by eliminating the donor site $[5,10,22,23]$. Heat or other treatments are used to deproteinate bone particles and eliminate immunogenicity risks $[25,28]$. Synthetic calcium phosphate ceramics with their excellent biocompatibility are common alternatives to autogenous bone [15].

Ideally, a BS should have specific biological and clinical particularities. Biologically, it should mediate recruitment of mesenchymal cells derived from host site and have bioactive effects on ossification (osteoinduction). Furthermore, it must be osteoconductive, providing three-dimensional scaffolds for the ingrowth of vessels and osteoprogenitor cells. Finally, it should be resorbable. Clinically, a BS should be easy to use, cost effective, and with adequate density to allow easy radiographic recognition during the entire healing process $[27,29]$. This feature is particularly important to radiographically follow the rate of resorption/substitution [30, 31].

Regarding material structure, particle size affects not only contact area but also the packing characteristics of the materials, which ultimately determines the macroporosity of a particulate graft $[32,33]$. It is also known that pore size exerts a major influence over the interaction of osteogenic cells with the biomaterial surface $[34,35]$. Biological integration requires pores that are greater than $100-150 \mathrm{~mm}$ in diameter to provide a blood supply to the tissues [27]. A BS should gradually degrade with time until it is completely replaced with vital new bone tissue. Moreover, a material's resorption rate should match the formation rate of the new bone tissue [29]. Biomaterial degradation that occurs too rapidly can exert a negative effect on bone regeneration processes, [24] and the presence of residual BS graft particles after bone healing may lead to composite tissue repair rather than to bone tissue regeneration [27].

The aim of this study was to evaluate some of physical and chemical properties in a variety of commercially available granulated mineral-based biomaterials that are frequently used for dental applications as bone substitutes and to compare them with autogenous bone.

\section{Materials and Methods}

This study evaluated the physicochemical characteristics of the eight commercially available bone substitutes of human, bovine, and synthetic origins. Each material was used in its lowest available particle size range, and all samples were obtained directly from their manufacturers in sealed vials and evaluated without alteration.

(i) DynaBlast (Keystone Dental, Inc., Burlington, MA) is a combination of mineralized and demineralized allogenic bone that is mixed with a proprietary poloxamer reverse-phase resorbable medium and processed into a paste or puttylike form $[28,36]$.

(ii) Puros bone allograft (Zimmer Dental, Inc., Carlsbad, CA) is an allogenic graft material treated by a proprietary process (Tutoplast, RTI Biologics, Inc., Alachua, FL) designed to inactivate pathogens and remove fat, cells, and antigens, while preserving the minerals and collagen matrix of the native bone tissue. After processing, the material is preserved by solvent dehydration, which can also help to ensure pathogen inactivation [13]. It is available in cortical, cancellous, and a cortical-cancellous mix in particle sizes ranging from 0.25 to $2 \mathrm{~mm}[26,37]$.

(iii) OsteoSponge allograft (Bacterin International, Inc., Belgrade, MT) consists of $100 \%$ of demineralized human cancellous bone, with no additional carrier materials. It is prepared using undisclosed methods that reportedly preserve native growth factors [25]. The granule size varies from 1 to $4 \mathrm{~mm}$.

(iv) BioOss (Geistlich Pharma AG, Wolhusen, Switzerland) xenogenic spongiosa granules are reported to be a natural bone mineral derived from bovine bone which contain carbonate apatite. Granules are rendered nonorganic through a proprietary extraction process that involves treatment with strong alkalis and organic solvents under high-temperature processing up to $300^{\circ} \mathrm{C}$, which allegedly renders the substrate antigenic and protein-free [37]. The material was used in granules of $0.25-1 \mathrm{~mm}$.

(v) Cerabone (AAP Biomaterials GmbH, Berlin, Germany) xenogenic granulate is a bovine bone material sintered at high temperature $\left(>1200^{\circ} \mathrm{C}\right)$, which retains the inorganic part of bone (hydroxyapatite) [38]. The material used was granulate of $0.5-1.0 \mathrm{~mm}$ in size.

(vi) Macrobone (Euroteknika Groupe, Sallanches, France) is a high-porosity (90\%), synthetic bone substitute made of pure $\beta$-TCP that is completely and rapidly resorbable [39]. Particle size varies between $0.15 \mathrm{~mm}$ and $2 \mathrm{~mm}$.

(vii) IngeniOs $\beta$-TCP (Zimmer Dental, Inc.) is a bioactive material made of silicated $\beta$-TCP of non-biologic origin. The structure is a porous biocompatible synthetic 
scaffold of ceramic material [40]. The size of the particles is $0.25-1 \mathrm{~mm}$.

(viii) IngeniOs HA (Zimmer Dental Inc.) is a synthetic spongious bone substitute. The structure is a porous scaffold that resembles cancellous bone. Particles are biocompatible and made of $100 \%$ hydroxyapatite ceramic with a putty phase of $\geq 95 \%$, and granules range $1-2 \mathrm{~mm}$ in size [41].

(ix) Autogenous bone samples were collected during mandibular third-molar surgery, rinsed with ethanol, dried in vacuum at room temperature, ground in an agate mortar, and sterilized by gamma irradiation $[42,43]$.

Atomic Absorption Spectroscopy (AAS) (WFX-210, RayLeigh, BRAIC, China) was used to determine the concentration of calcium ions in the bone substitutes by quantifying the release of calcium and phosphorous from the graft material in demineralized water. For this aim, standards for calcium and phosphorous within the range between 0.5 and $10 \mu \mathrm{g} / \mathrm{L}$ were prepared, and $0.4 \mathrm{mg}$ of each biomaterial (all nine samples) was immersed in $100 \mathrm{~mL}$ of $0.9 \% \mathrm{NaCl}$ and the $\mathrm{pH}$ was adjusted at 7 by using hydrochloric acid $(0.1 \mathrm{~N})$. The variation of $\mathrm{Ca}$ concentration was determined at $\mathrm{D}_{0}$ (day 0 ), $\mathrm{D}_{2}$ (day two), and each week after, until the sixth week. The concentration was calculated based on the Beer-Lambert law [44].

LASER Diffraction (LD) was used to determine particle size by evaluating the distribution of the granules using a laser scattering particle size analyzer (Patrica LA-950 V2 Horiba Instruments, Japan). The measurement method relied on the Mie scattering theory [45]. Using an ultrasonic probe with measuring time of $20 \mathrm{~s}$ at a frequency of $20 \mathrm{kHz}$, the unit's measuring range varied between 0.01 and $3.00 \mu \mathrm{m}$. The devise was equipped with an optical system of two light sources, a laser diode of approximately $1.6 \mathrm{~mW}$ with $\lambda=650 \mathrm{~nm}$, and a $405 \mathrm{~nm}$ light emitting diode of approximately $0.3 \mathrm{~mW}$. Large particles scatter light at small angles relative to the laser beam and small particles scatter light at large angles. The particle size is reported as a volume equivalent sphere diameter $[43,46]$. Samples were well mixed and homogenized in their powder state prior to their analysis. Average particle size and distribution were calculated for all nine biomaterials and autogenous bone.

$X$-ray Diffraction (XRD) (D8 Advance, Bruker Corporation, Billerica, MA) was used to identify phase and composition features and qualitatively evaluate the crystallinity of all study materials. Homogenized powder samples (1-2 g) were compressed in polyvinyl chloride lenses (diameter $2.5 \mathrm{~cm}$, thickness $2 \mathrm{~mm}$ ) and measured using a diffract meter (copper anticathode $\lambda \mathrm{K} \alpha=0.154060 \mathrm{~nm}$ ). A range of $2 \theta$ between $x^{\circ}$ and $y^{\circ}$ was chosen to obtain maximum information about crystal phases. Collected diffract grams were analyzed by software EVA (EVA, Bruker Corporation) based on powder diffraction files provided by the International Center for Diffraction Data (Newtown Square, PA). Crystallite size analysis was calculated using the peak broadening of XRD reflection that is used to estimate the crystallite size in an orthogonal direction to the crystal plane according to the following formula:

$$
X_{s}=\frac{0.9 \lambda}{(\mathrm{FWHM} \times \cos \theta)},
$$

where $X_{s}$ is the crystallite size in nanometer, $\lambda$ is the wavelength of $X$-ray beam in nanometer $(\lambda=0.15406 \mathrm{~nm}$ in our case), and FWHM is the full width at half maximum for the diffraction angle at $2 \theta=25.9^{\circ}$ that was selected according to (002) Miller's plane family [47].

\section{Results}

AAS results of calcium concentration over the observation period are summarized in Table 1. Cerabone showed less calcium release than BioOss. In the synthetic xenograft category, Macrobone displayed a high calcium release concentration $(17.30 \mathrm{mg} / \mathrm{g})$, compared to IngeniOs HA $(2.92 \mathrm{mg} / \mathrm{g})$ and IngeniOs $\beta$-TCP $(2.83 \mathrm{mg} / \mathrm{g})$. In the allograft group, OsteoSponge revealed the lowest calcium release concentration $(4.05 \mathrm{mg} / \mathrm{g})$. The calcium concentration of Puros $(24.94 \mathrm{mg} / \mathrm{g})$ was comparable to autogenous bone (20.15 mg/g).

The particles median size $\mathrm{D}_{50}$ (in volume percentages), the particle size range expressed by the $10 \%$ and $90 \%$ percentiles $\left(D_{10}\right.$ and $\left.D_{90}\right)$, and the particles size ranges reported by the manufacturers as determined by the LD measurements are all presented in Table 2.

Results showed that BioOss had the lowest median particle size $(1.32 \mu \mathrm{m})$ followed by Ingenios $\beta$-TCP $(6.72 \mu \mathrm{m})$, while OsteoSponge had the highest one $(902.41 \mu \mathrm{m})$.

The median size of Macrobone $(262.37 \mu \mathrm{m})$ was close to autogenous bone $(282.1 \mu \mathrm{m})$. The narrowest size distribution was observed with BioOss $(0.26-8.92 \mu \mathrm{m})$, followed by Ingenios $\beta$-TCP (3.90-15.18 $\mu \mathrm{m})$. The widest size distribution was observed with OsteoSponge (174.62-2301.84 $\mu \mathrm{m}$ ) followed by DynaBlast (39.24-1754.62 $\mu \mathrm{m})$.

$\mathrm{X}$-ray diffractograms for all bone substitutes are shown in Figure 1. They represent the intensity of X-ray (cps) as a function of the diffraction angles ( 2 theta, $\theta$ ).

Results of the XRD experiments that are indicative for the chemical composition of the BS are shown in Table 3 except for DynaBlast, as the puttylike material was not granular in form. All study materials showed small amounts of impurities. These materials diffract more and less the Xray, which means diverse degrees of crystallinity, as indicated in the different peaks widths.

The common crystal phase was calcium phosphate silicate hydroxide $\left(\mathrm{Ca}_{5}\left(\mathrm{PO}_{4}\right)_{2.85}\left(\mathrm{SiO}_{4}\right)_{0.15}(\mathrm{OH})\right)$ in BioOss, Ingenios $\mathrm{HA}$, Puros, OsteoSponge, and autogenous bone. Macrobone was composed from calcium phosphate $\left(\mathrm{Ca}_{3}\left(\mathrm{PO}_{4}\right)_{2}\right)$. Cerabone and Ingenios $\beta$-TCP were composed, respectively, of calcium gadolinium oxide phosphate $\left(\mathrm{Ca}_{8} \mathrm{Gd}_{2}\left(\mathrm{PO}_{4}\right) 6 \mathrm{O}_{2}\right)$ and sodium calcium iron phosphate $\left(\mathrm{Na}_{2} \mathrm{Ca}_{19} \mathrm{Fe}_{0.667}\left(\mathrm{PO}_{4}\right)_{14}\right)$ as the main crystal phases. Except for Ingenios $\beta$-TCP, Macrobone, and Osteosponge, all samples were crystallized at different levels of crystallinity in hexagonal systems. 


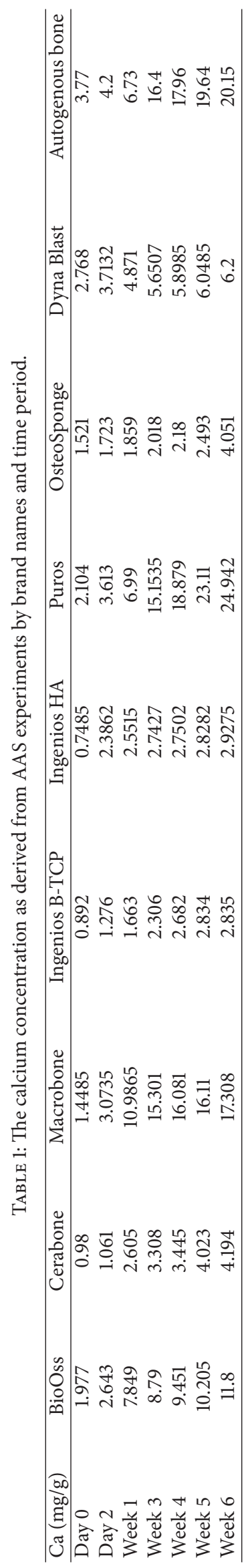


TABLE 2: Particle size parameters in volume percentage of the samples.

\begin{tabular}{lccc}
\hline Sample & $\begin{array}{c}\text { Median size } \\
\left(\mathrm{D}_{50} \mu \mathrm{m}\right)\end{array}$ & $\begin{array}{c}\text { Size range } \\
\left(\mathrm{D}_{10}-\mathrm{D}_{90} \mu \mathrm{m}\right)\end{array}$ & $\begin{array}{r}\text { Size range reported } \\
\text { By producers }(\mu \mathrm{m})\end{array}$ \\
\hline Bio-Oss & 1.32 & $0.26-8.92$ & $250-1000$ \\
Cerabone & 663.31 & $174.62-1337.48$ & $500-1000$ \\
Macrobone & 262.37 & $22.79-517.2$ & $150-500$ \\
Ingenios B-TCP & 6.72 & $3.90-15.18$ & $250-1000$ \\
Ingenios HA & 592.39 & $8.82-1337.48$ & $1000-2000$ \\
Puros & 630.47 & $174.62-1167.72$ & $250-2000$ \\
OsteoSponge & 902.41 & $152.45-2301.84$ & $1000-4000$ \\
Dyna Blast & 777.14 & $39.24-1754.62$ & Nonindicated \\
Autogenous bone & 282.1 & $90.5-465.15$ & \\
\hline
\end{tabular}
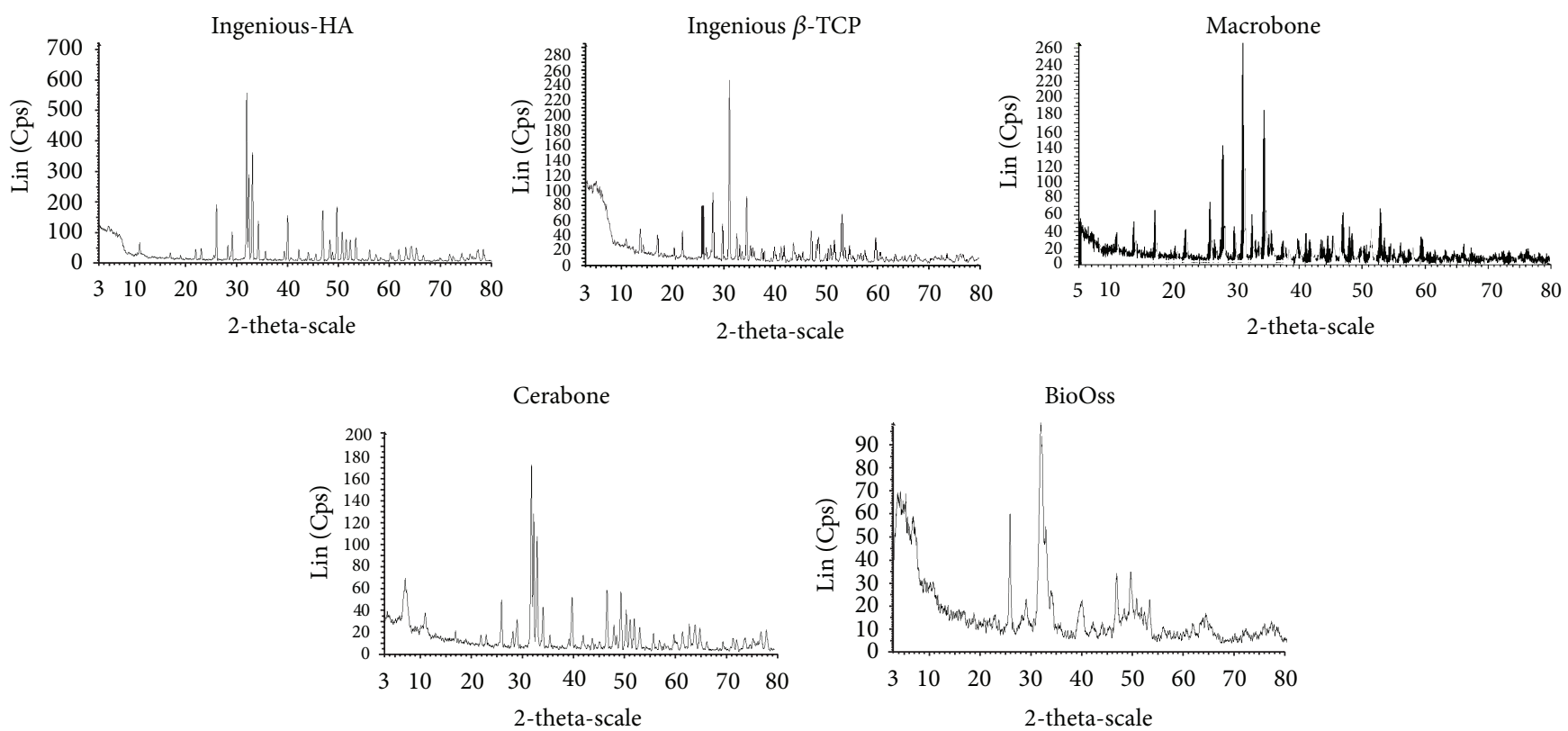

(a)
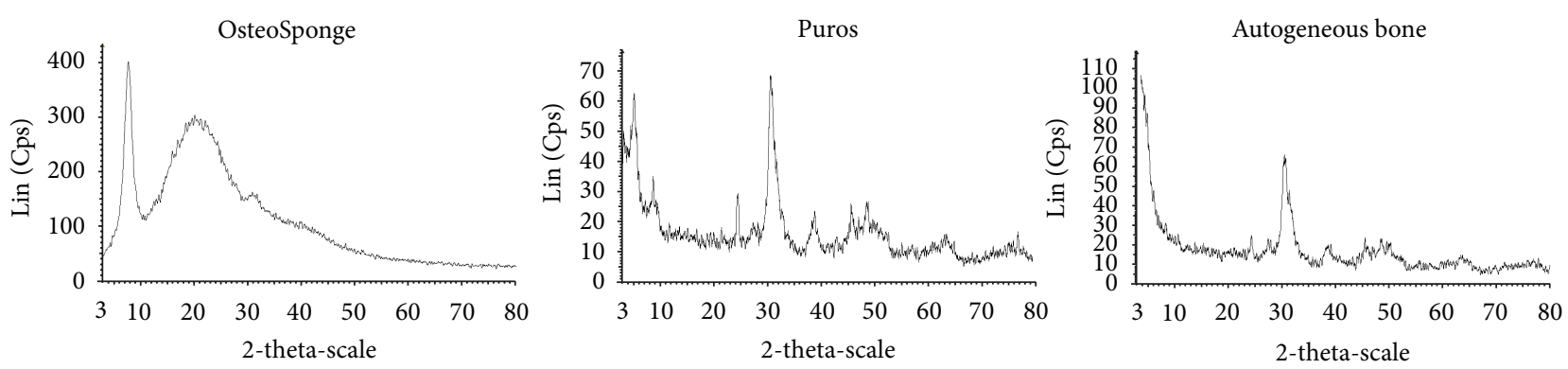

(b)

FIGURE 1: X-ray diffraction data for all investigated samples. (a) Ingenios HA, Ingenios $\beta$-TCP, Marrowbone, Cerabone, and BioOss have well defined peaks, which reflects their well-crystallized components. (b) OsteoSponge, Puros, and autogenous bone have noisy diffractograms revealing less crystallinity.

The $a / c$ or $b / c$ ratios $(9.42 / 6.89)$ indicated a flat structure parallel to $A_{6}$ axis. Such geometry may enhance the settlement properties of these particles. For Ingenios $\beta$-TCP and Macrobone, $a$ and $b$ crystal dimensions in the rhombohedra system were relatively too close to $a$ and $b$ dimensions of the other bones crystallized in hexagonal system. Nevertheless, $c$ length $(37.3 \AA)$ in Ingenios $\beta$-TCP and Macrobone was 5.4 times greater than $c$ ( $6.89 \AA)$ length in the other bones. Hence, settlement may be oriented preferably orthogonal to $A_{3}$ axis. In Ingenios $\beta$-TCP and Macrobone, crystal size was 


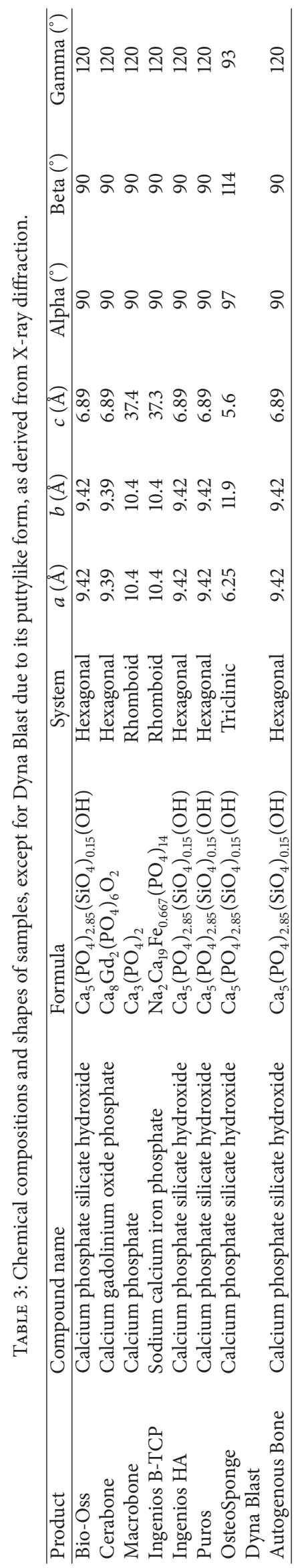




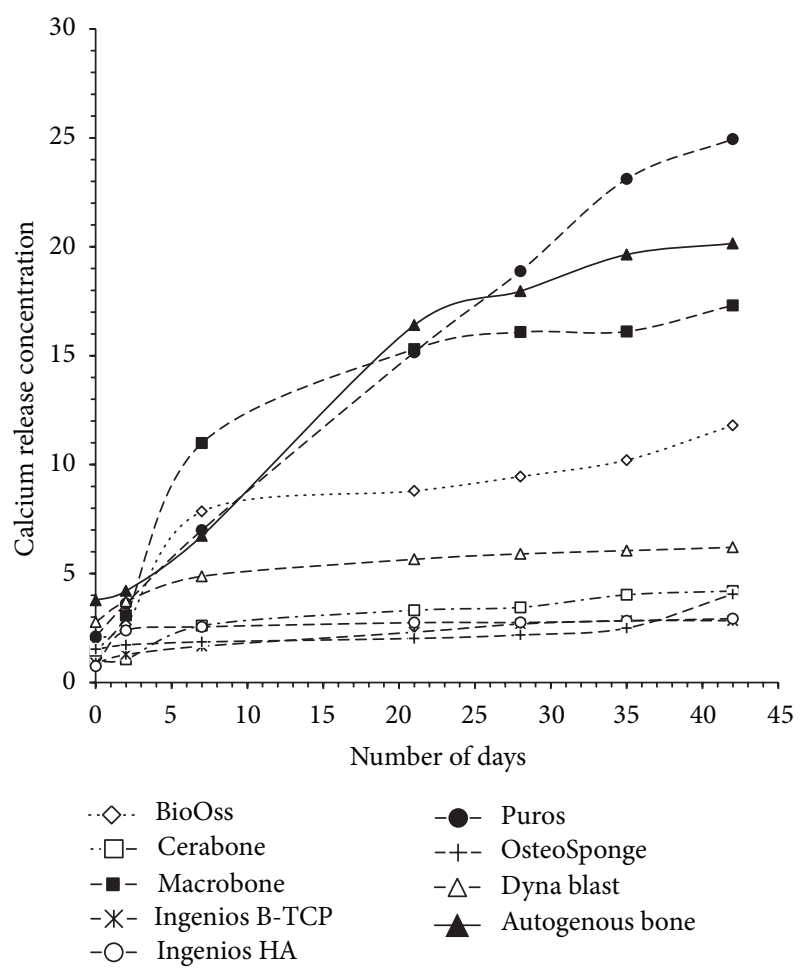

FIGURE 2: AAS results from calcium concentration over the observation period of all tested bone substitutes. $Y$-axes represent calcium release in $\mathrm{mg} / \mathrm{g}$ and $X$ axes represent day's number.

greater than that of the other bones. OsteoSponge was the only sample crystallized in the triclinic system.

\section{Discussion}

The higher the calcium concentration in a biomaterial, the more prone it will be to degradation $[3,42,43]$. The acidic buffer, to some extent, mimics the acidic environment during osteoclastic activity or bone resorption [3, 42, 43]. In our study, different biomaterials had different calcium releasing characteristics. This could be explained by the fact that the speed of BS biodegradability in vivo or in vitro depends on the material's composition, particle size, crystallinity, porosity, and preparation $[3,38,42,43,48]$.

From the particle size data, it can be concluded that, in general, size ranges measured for tested materials were different from those reported by manufacturers who do not specify the technique used in the crystalline material's characterization and could explain the noticed differences [49-54]. However, it should be kept in mind that the granules under analysis differed not only in their size but also in their physicochemical properties.

The influence of properties and characteristics of BS on biological response cannot be easily predicted as the published studies involve different types of BS in different particle size ranges. Regarding the ranges of particle size that were tested in the present investigation, there was no relation between the sizes of particles and calcium concentration with the time (Figure 2).

$\mathrm{X}$-ray diffractograms give a clear idea about the crystallinity of the analyzed materials and their crystal phases. $\mathrm{HA}$, Ingenios $\beta$-TCP, Macrobone, Cerabone, and BioOss have well-defined peaks which reflects their well-crystallized components; OsteoSponge, Puros, and autogenous bone have noisy diffractograms revealing the presence of amorphous structure or at least noncrystallized faces of the materials.

All bone substitutes show a typical and most intense diffraction at $2 \theta$ of $32^{\circ}$ since phosphate is the common component in all used materials. Crystal phases were identified using the powder diffraction files, provided by the Interactive Center for Diffraction Data.

XRD diffractograms of various materials, including human bone, were quite similar to common crystal phase calcium phosphate silicate hydroxide $\left(\mathrm{Ca}_{5}\left(\mathrm{PO}_{4}\right)_{2.85}\right.$. $\left.\left(\mathrm{SiO}_{4}\right)_{0.15}(\mathrm{OH})\right)$ except for Cerabone, which showed the presence of gadolinium in its composition, and Ingenios $\beta$-TCP, which showed the presence of iron. However, silicates, when they are present, are not major components of the crystal phases, since their stoichiometry compared to phosphate (2.85) were considerably negligible (0.15). Iron and sodium are also negligible compared to calcium in Ingenios $\beta$-TCP. Along with calcium, they help to compensate the negative charges of phosphate. It must be highlighted that, in bone and all bone substitutes, $\mathrm{Ca}$ to $\mathrm{P}$ ratios fluctuated between 1.75 and 1.33. This could mean that calcium was the major element that compensated phosphate charges.

It is not clear why gadolinium was present in the crystal phase of Cerabone. One possible explanation could be the iron oxidized at high temperature since the product was subjected to high-temperature calcination $\pm 1200^{\circ} \mathrm{C}$ [55]. Another explanation could be that it was used for its property to enhance the resistance of alloys against oxidation. It should be noted that natural gadolinium occurs in monazite mineral (rare earth phosphate) and gadolinium salt has an exceptionally high absorption of neutrons and therefore is used for shielding in radiography as a contrast agent [56].

Nevertheless, we could not assert if gadolinium in those studied samples naturally occurred or was purposely added.

XRD diffractograms showed that all samples, including natural bone, proved to have the same anisotropic crystal size $(9.42 \AA$ in $a$-and $b$-directions and $6.89 \AA$ in $c$-direction with alpha and beta $90^{\circ}$ and gamma $120^{\circ}$ ); Ingenios $\beta$-TCP and Macrobone showed different anisotropic size $10.4 \AA$ in $a$ - and $b$-directions and $37,3 \AA$ in $c$-direction with alpha and beta $90^{\circ}$ and gamma $120^{\circ}, 6.25 \AA$ in $a$-direction, $11.9 \AA$ in $b$-direction, and $5.6 \AA$ in $c$-direction with alpha 97 and beta $114^{\circ}$ and gamma $93^{\circ}$, respectively. These results demonstrated that crystal shapes of the BS and autogenous bone had a similar, hexagonal shape; only Ingenios $\beta$-TCP and Macrobone showed a rhomboid design and OsteoSponge a triclinic shape. This structure is the poorest system in the symmetric properties [57].

Eight different bone-grafting materials were herein investigated, and the results were compared to autogenous bone. Even when similar chemical characteristics were found, 
significant differences were detected in terms of calcium concentrations, particle sizes, and crystallinity. Although these morphological differences greatly influence in vivo behavior of the biomaterial, they are often not taken into consideration when the samples' biological performance is evaluated. It is believed that results provided for biomaterials investigated will be most useful to fully understand their clinical behavior and response. Since the bone substitute of choice depends largely on the possible clinical application and its associated biological and mechanical needs, it is important not to assume that all bone substitutes will show the same pattern of performance and that the validation of a bone substitute in one clinical site may not necessarily predict its identical performance in another anatomical location. Hopefully in the future, hybrid or complex combination products that include cells, growth factors, and/or gene therapy in combination will be likely to provide oral surgeons more effective tools for bone defects reparation. In this regard, it is obvious that further studies are warranted and a new international standard for characterization, classification, and identification of implantable materials is needed.

\section{Conclusion}

Commercial bone substitutes significantly differ in terms of calcium concentration, particle size, and crystallinity from autogenous bone, which may affect their clinical applications and performance.

\section{Conflict of Interests}

The authors do not have any financial interests in the products or information listed in this paper. The authors declare that they have no conflict of interests.

\section{Acknowledgments}

The authors would like to thank Manal Houhou, Sarah Hadda, Sahar Rihan, and Hussein Bassal for their excellent technical assistance. This project was supported by a grant from the Ecole Doctorale, Lebanese University.

\section{References}

[1] M. I. Kay, R. A. Young, and A. S. Posner, "Crystal structure of hydroxyapatite," Nature, vol. 204, no. 4963, pp. 1050-1052, 1964.

[2] U. Ripamonti and R. M. Klar, "Regenerative frontiers in craniofacial reconstruction: Grand challenges and opportunities for the mammalian transforming growth factor- $\beta$ proteins," Frontiers in Physiology, vol. 1, no. 1, article 143, 2010.

[3] R. Z. LeGeros, "Calcium phosphate-based osteoinductive materials," Chemical Reviews, vol. 108, no. 11, pp. 4742-4753, 2008.

[4] H. Orimo, "The mechanism of mineralization and the role of alkaline phosphatase in health and disease," Journal of Nippon Medical School, vol. 77, no. 1, pp. 4-12, 2010.

[5] R. A. Kenley, K. Yim, J. Abrams et al., "Biotechnology and bone graft substitutes," Pharmaceutical Research, vol. 10, no. 10, pp. 1393-1401, 1993.
[6] M. S. Block and J. N. Kent, "Sinus augmentation for dental implants: the use of autogenous bone," Journal of Oral and Maxillofacial Surgery, vol. 55, no. 11, pp. 1281-1286, 1997.

[7] S. L. Wheeler, "Sinus augmentation for dental implants: the use of alloplastic materials," Journal of Oral and Maxillofacial Surgery, vol. 55, no. 11, pp. 1287-1293, 1997.

[8] A. S. Greenwald, S. D. Boden, V. M. Goldberg, Y. Khan, C. T. Laurencin, and R. N. Rosier, "Bone-graft substitutes: facts, fictions, and applications," Journal of Bone and Joint Surgery A, vol. 83, no. 2, pp. 98-103, 2001.

[9] S. N. Parikh, "Bone graft substitutes: past, present, future," Journal of Postgraduate Medicine, vol. 48, no. 2, pp. 142-148, 2002.

[10] C. G. Finkemeier, "Bone-grafting and bone-graft substitutes," Journal of Bone and Joint Surgery A, vol. 84, no. 3, pp. 454-464, 2002.

[11] G. K. B. Sandor, T. C. Lindholm, and C. M. L. Clokie, "Bone regeneration of the cranio-maxillofacial and dento-alveolar skeletons in the framework of tissue engineering," in Topics in Tissue Engineering, N. Ashammakhi and P. Ferretti, Eds., chapter 7, pp. 1-46, 2003.

[12] B. Ben-Nissan, "Natural bioceramics: from coral to bone and beyond," Current Opinion in Solid State and Materials Science, vol. 7, no. 4-5, pp. 283-288, 2003.

[13] D. A. di Stefano, L. Artese, G. Iezzi et al., "Alveolar ridge regeneration with equine spongy bone: a clinical, histological, and immunohistochemical case series," Clinical Implant Dentistry and Related Research, vol. 11, no. 2, pp. 90-100, 2009.

[14] M. Vallet-Regí and J. M. González-Calbet, "Calcium phosphates as substitution of bone tissues," Progress in Solid State Chemistry, vol. 32, no. 1-2, pp. 1-31, 2004.

[15] K. A. Hing, L. F. Wilson, and T. Buckland, "Comparative performance of three ceramic bone graft substitutes," The Spine Journal, vol. 7, no. 4, pp. 475-490, 2007.

[16] D. M. Dohan Ehrenfest, B. S. Kang, G. Sammartino et al., "Guidelines for the publication of articles related to implant surfaces and design from the POSEIDO: a standard for surface characterization," POSEIDO, vol. 1, no. 1, p. 15, 2013.

[17] J. P. Davidas, "Looking for a new international standard for characterization, classification and identification of surfaces in implantable materilals: the long march for the evaluation of dental implant surfaces has just began," POSEIDO, vol. 2, no. 1, pp. 1-5, 2014.

[18] J. M. Rueger, W. Linhart, and D. Sommerfeldt, "Biological reaction to calcium-phosphate ceramic implants. Results of animal experiments," Orthopade, vol. 27, no. 2, pp. 89-95, 1998.

[19] M. Bohner, "Calcium orthophosphates in medicine: from ceramics to calcium phosphate cements," Injury, vol. 31, no. 4, pp. D37-D47, 2000.

[20] M. Bohner, "Physical and chemical aspects of calcium phosphates used in spinal surgery," European Spine Journal, vol. 10, no. 2, pp. S114-S121, 2001.

[21] I. Bouchlariotou, J. P. Bernard, J. P. Carrel, and L. Vazquez, "Long-term stability of osseointegrated implants in bone regenerated with a collagen membrane in combination with a deproteinized bovine bone graft: 5 -year follow-up of 20 implants," POSEIDO, vol. 1, no. 1, pp. 45-53, 2013.

[22] R. Toeroek and D. M. Dohan Ehrenfest, "The concept of ScrewGuided Bone Regeneration (S-GBR). Part 3: Fast Screw-Guided Bone Regeneration (FS-GBR) in the severely resorbed preimplant posterior mandible using allograft and Leukocyte- and 
Platelet-Rich Fibrin (L-PRF): a 4-year follow-up," POSEIDO, vol. 2, no. 2, pp. 93-100, 2013.

[23] R. Toeroek R and D. M. D. Ehrenfest, "The concept of screwguided bone regeneration (S-GBR). Part 2: S-GBR in the severely resorbed preimplant posterior mandible using bone xenograft and leukocyte- and platelet-rich fibrin (L-PRF): a 5year follow-up," POSEIDO, vol. 2, no. 2, pp. 85-92, 2013.

[24] H. Sung, C. Meredith, C. Johnson, and Z. S. Galis, "The effect of scaffold degradation rate on three-dimensional cell growth and angiogenesis," Biomaterials, vol. 25, no. 26, pp. 5735-5742, 2004.

[25] J. Glowacki, "A review of osteoinductive testing methods and sterilization processes for demineralized bone," Cell and Tissue Banking, vol. 6, no. 1, pp. 3-12, 2005.

[26] S. T. Moore, J. M. Katz, R. M. Zhukauskas et al., "Osteoconductivity and osteoinductivity of Puros (R) DBM putty," Journal of Biomaterials Applications, vol. 26, no. 2, pp. 151-171, 2011.

[27] T. Traini, A. Piatelli, S. Caputi et al., "Regeneration of human bone using different bone substitute biomaterials," Clinical Implant Dentistry and Related Research, 2013.

[28] C. Schöpf, W. Daiber, and D. Tadic, "Tutoplast processed allografts and xenografts," in 3D Block Technique in from Image Diagnostics to Block Graft Bone Regeneration, M. Jacotti and P. Antonelli, Eds., chapter 5, pp. 54-75, RC Libri, Milano, Italy, 2005.

[29] C. P. Klein, A. A. Driessen, K. de Groot, and A. van den Hooff, "Biodegradation behavior of various calcium phosphate materials in bone tissue," Journal of Biomedical Materials Research, vol. 17, no. 5, pp. 769-784, 1983.

[30] S. Platzer, A. Wildburger, M. Lorenzoni et al., "Human cadaver study evaluating a new measurement technique for graft volumes after sinus floor elevation," Clinical Implant Dentistry and Related Research, vol. 16, no. 2, pp. 212-222, 2012.

[31] C. Dellavia, S. Speroni, G. Pellegrini, A. Gatto, and C. Maiorana, "A new method to evaluate volumetric changes in sinus augmentation procedure," Clinical Implant Dentistry and Related Research, vol. 19, 2013.

[32] Z. Schwartz and B. D. Boyan, "Underlying mechanisms at the bone-biomaterial interface," Journal of Cellular Biochemistry, vol. 56, no. 3, pp. 340-347, 1994.

[33] X. Li, C. A. van Blitterswijk, Q. Feng, F. Cui, and F. Watari, “The effect of calcium phosphate microstructure on bone-related cells in vitro," Biomaterials, vol. 29, no. 23, pp. 3306-3316, 2008.

[34] A. C. C. da Cruz, M. T. Pochapski, J. B. Daher, J. C. Z. da Silva, G. L. Pilatti, and F. A. Santos, "Physico-chemical characterization and biocompatibility evaluation of hydroxyapatites," Journal of Oral Science, vol. 48, no. 4, pp. 219-226, 2006.

[35] A. L. Carvalho, P. E. P. Faria, M. F. M. Grisi et al., "Effects of granule size on the osteoconductivity of bovine and synthetic hydroxyapatite: a histologic and histometric study in dogs," The Journal of Oral Implantology, vol. 33, no. 5, pp. 267-276, 2007.

[36] T. Irinakis, "Efficacy of injectable demineralized bone matrix as graft material during sinus elevation surgery with simultaneous implant placement in the posterior maxilla: clinical evaluation of 49 sinuses," Journal of Oral and Maxillofacial Surgery, vol. 69, no. 1, pp. 134-141, 2011.

[37] C. M. Schmitt, H. Doering, T. Schmidt, R. Lutz R, F. W. Neukam, and K. A. Schlegel, "Histological results after maxillary sinus augmentation with Straumann, BoneCeramic, Bio-Oss, Puros, and autologous bone. A randomized controlled clinical trial," Clinical Oral Implants Research, vol. 24, no. 5, pp. 576-585, 2013.
[38] D. Tadic and M. Epple, "A thorough physicochemical characterisation of 14 calcium phosphate-based bone substitution materials in comparison to natural bone," Biomaterials, vol. 25, no. 6, pp. 987-994, 2004.

[39] D. Chappard, B. Guillaume, R. Mallet, F. Pascaretti-Grizon, M. F. Baslé, and H. Libouban, "Sinus lift augmentation and $\beta$-TCP: a microCT and histologic analysis on human bone biopsies," Micron, vol. 41, no. 4, pp. 321-326, 2010.

[40] A. M. Pietak, J. W. Reid, M. J. Stott, and M. Sayer, "Silicon substitution in the calcium phosphate bioceramics," Biomaterials, vol. 28, no. 28, pp. 4023-4032, 2007.

[41] M.-J. Lee, S.-K. Sohn, K.-T. Kim et al., "Effect of hydroxyapatite on bone integration in a rabbit tibial defect model," Clinics in Orthopedic Surgery, vol. 2, no. 1, pp. 90-97, 2010.

[42] F. Peters, K. Schwarz, and M. Epple, "The structure of bone studied with synchrotron X-ray diffraction, X-ray absorption spectroscopy and thermal analysis," Thermochimica Acta, vol. 361, no. 1-2, pp. 131-138, 2000.

[43] M. Figueiredo, J. Henriques, G. Martins, F. Guerra, F. Judas, and H. Figueiredo, "Physicochemical characterization of biomaterials commonly used in dentistry as bone substitutescomparison with human bone," Journal of Biomedical Materials Research B, vol. 92, no. 2, pp. 409-419, 2010.

[44] R. García and A. P. Báez, "Atomic Absorption Spectrometry (AAS)," in Atomic Absorption Spectroscopy, M. A. Farrukh, Ed., chapter 1, pp. 1-13, InTech, 2012.

[45] T. Wriedt, "Mie theory: a review," in The Mie Theory, W. Hergert and T. Wriedt, Eds., vol. 169 of Springer Series in Optical Sciences, pp. 53-71, Springer, Berlin, Germany, 2012.

[46] S. Marković, L. Veselinović, M. J. Lukić et al., "Synthetical bone-like and biological hydroxyapatites: a comparative study of crystal structure and morphology," Biomedical Materials, vol. 6, no. 1, pp. 45-50, 2011.

[47] P. K. Harold and E. L. Alexander, X-Ray Diffraction Procedures: For Polycrystalline and Amorphous Materials, Wiley- Interscience, New York, NY, USA, 2nd edition, 1974.

[48] G. Hannink and J. J. C. Arts, "Bioresorbability, porosity and mechanical strength of bone substitutes: what is optimal for bone regeneration?" Injury, vol. 42, no. 2, pp. S22-S25, 2011.

[49] Geistlich Biomaterials Inc., "Product information on BioOss," http://www.geistlich.ch/index.cfm?dom=2\&rub=42\&id=100064.

[50] Bacterin, product information on Osteosponge, 2014, http:// bacterin.com/products/osteosponge/.

[51] Zimmer dental, products, regenerative, bone grafts, information on Puros, HA, $\beta$-TCP, 2014, http://www.zimmerdental.com/products/regenerative/rg_overview.aspx.

[52] Botiss Biomaterials, Product Information on Cerabone, 2014, https://www.botiss.com/en/content/cerabone\%C2\%AE.

[53] KeyStone Dental Inc. product information on DynaBlast, 2014, http://www.keystonedental.com/products/dynablast/.

[54] Euroteknika, "Product information on MacroBone," 2014, http://www.euroteknika-implants.com/EN/IMG/pdf/FP_Macrobone_EN.pdf.

[55] A. Gschneidner Jr., V. K. Pecharsky, and A. O. Tsokol, "Recent developments in magnetocaloric materials," Reports on Progress in Physics, vol. 68, no. 6, pp. 1479-1539, 2005.

[56] I. E. Chesnick, C. B. Fowler, J. T. Mason, and K. Potter, "Novel mineral contrast agent for magnetic resonance studies of bone implants grown on a chick chorioallantoic membrane," Magnetic Resonance Imaging, vol. 29, no. 9, pp. 1244-1254, 2011.

[57] H. D. Flack, "Chiral and achiral crystal structures," Helvetica Chimica Acta, vol. 86, no. 4, pp. 905-921, 2003. 

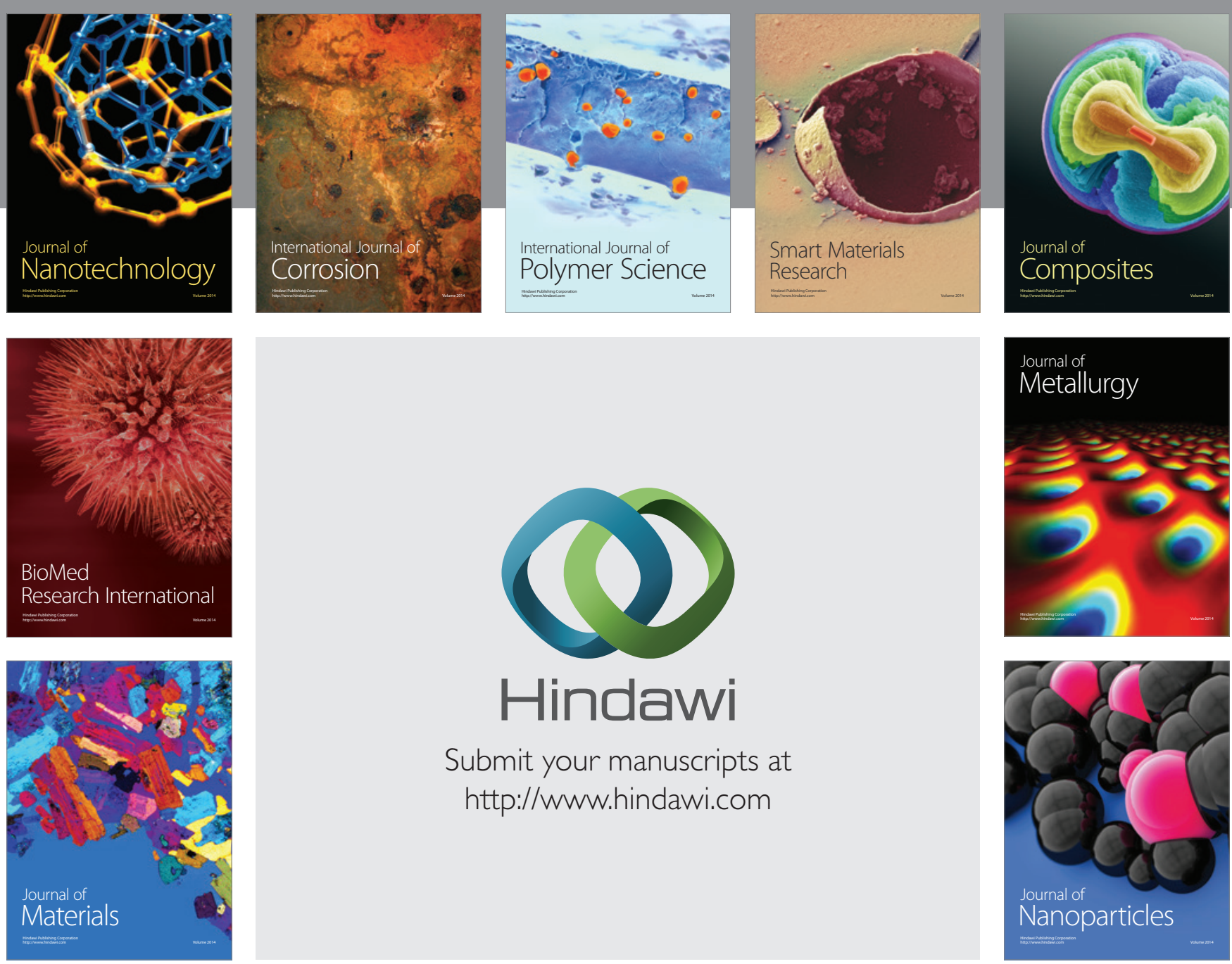

Submit your manuscripts at http://www.hindawi.com
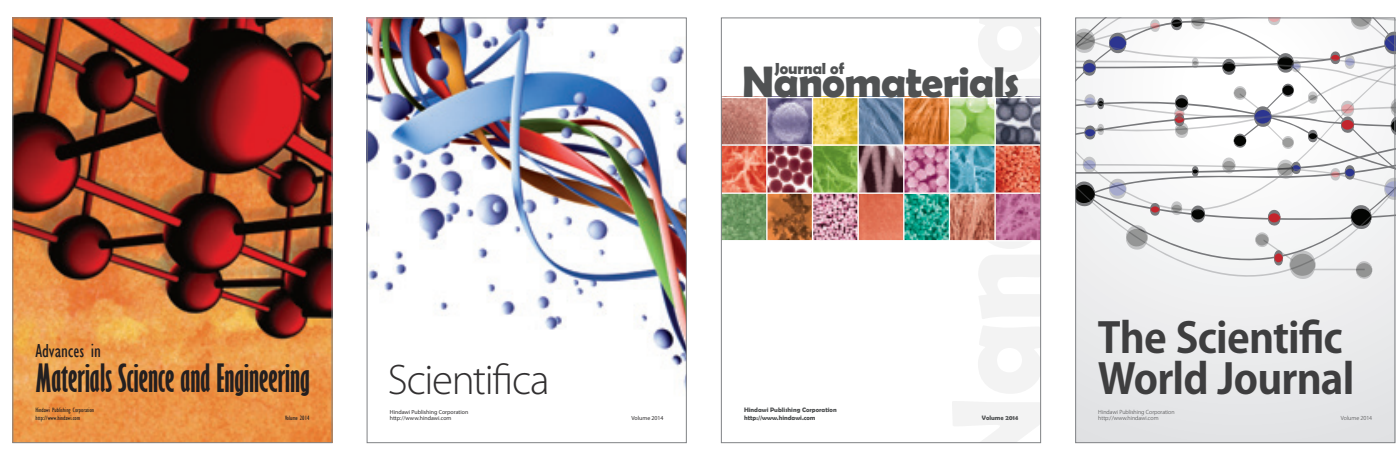

\section{The Scientific World Journal}
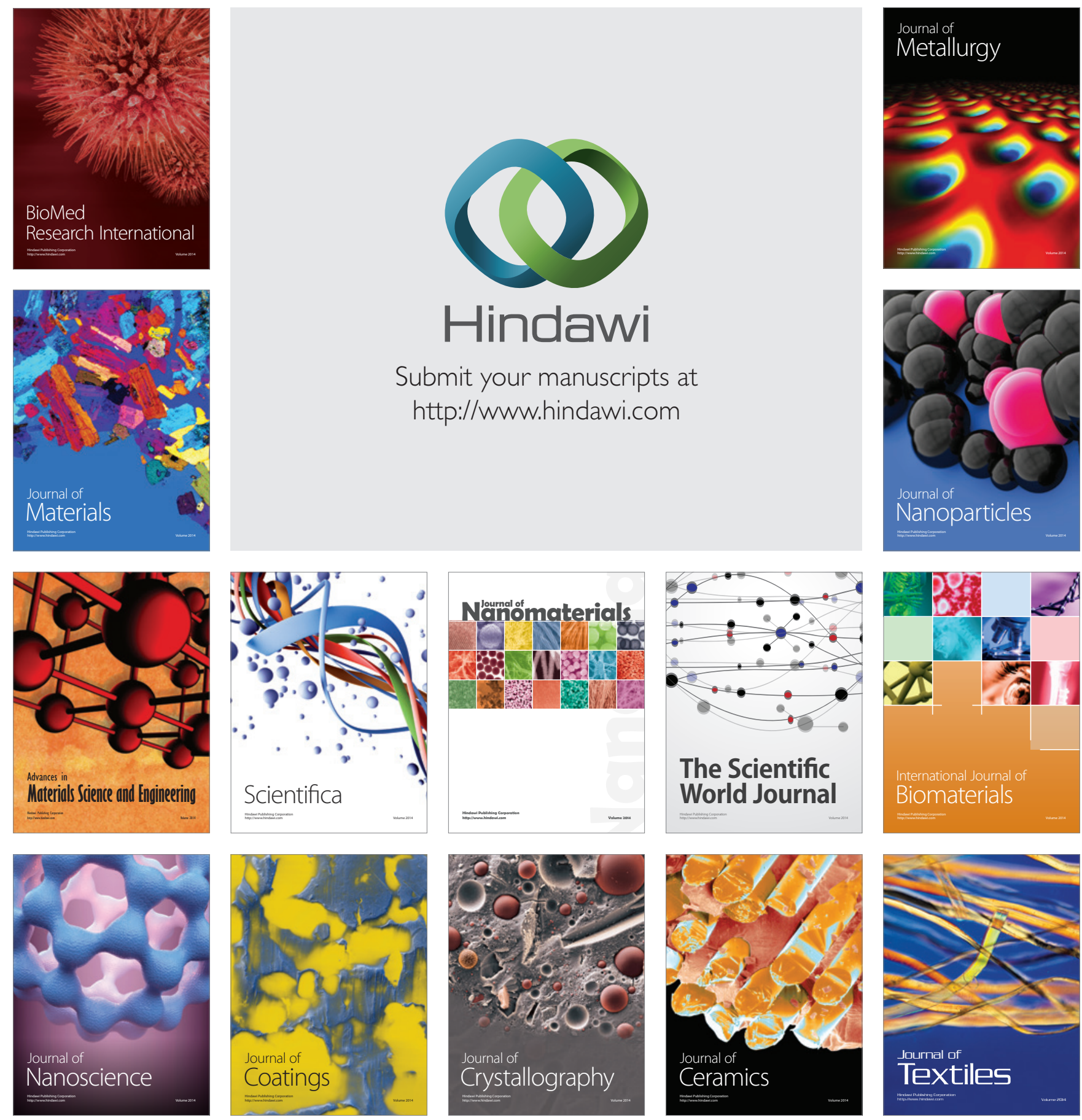